\title{
Realized and potential larval connectivity in the Southern California Bight
}

\author{
J. R. Watson ${ }^{1, *}$, S. Mitarai1,4 ${ }^{1,}$ D. A. Siegel ${ }^{1}$, J. E. Caselle ${ }^{2}$, C. Dong ${ }^{3}$, J. C. McWilliams ${ }^{3}$ \\ ${ }^{1}$ Institute for Computational Earth System Science, and ${ }^{2}$ Marine Science Institute, University of California, Santa Barbara, \\ California 93106, USA \\ ${ }^{3}$ Institute of Geophysics and Planetary Physics, University of California, Los Angeles, California 90095, USA \\ ${ }^{4}$ Present address: Marine Biophysics Unit, Okinawa Institute of Science and Technology, Okinawa 904-0411, Japan
}

\begin{abstract}
Populations of many nearshore marine species are connected through the dispersal of their larvae. In this paper, larval connectivity patterns in the Southern California Bight are explored using 2 quantities: potential and realized larval connectivity. Potential connectivity is defined as the probability of larval transport from a source to a destination location and is quantified using Lagrangian particle simulations. Realized connectivity is the product of potential connectivity with larval production and can be used to estimate larval settlement patterns. Potential and realized connectivity patterns are quantified for kelp bass Paralabrax clathratus, kelp rockfish Sebastes atrovirens, and red abalone Haliotis rufescens, 3 species with a range of larval dispersal characteristics. Connectivity patterns were found to be both heterogeneous, with locations having different source and destination strengths, and asymmetric, with directionality in larval transport. Both potential and realized connectivity were strongly influenced by the length and timing of the spawning season as well as planktonic larval duration. For kelp bass and kelp rockfish, a strong correspondence was found between realized and potential destination locations, suggesting that circulation processes have a dominant role in shaping the spatial distribution of these 2 species. Strong temporal variability in realized larval connectivity was observed on seasonal and inter-annual time scales (particularly between El Niño and La Niña conditions). These results provide novel information for use in marine fisheries and conservation management.
\end{abstract}

KEY WORDS: Larval connectivity - Ocean circulation - Lagrangian particle simulation - Larval production $\cdot$ Spatial management

\section{INTRODUCTION}

Many nearshore marine species have a larval stage where ocean currents have a strong influence on dispersal. The distances traveled during this larval stage can be relatively large when compared with adult home ranges and can set up complex patterns in source (where larvae are spawned) to destination (where larvae settle) connectivity (Largier 2003, Kinlan et al. 2005). Larval connectivity affects many processes, including stock and meta-population dynamics, population genetic structure, species ranges, and the spread of invasive species (Roughgarden et al.
1988, Gaylord et al. 2005, Byers \& Pringle 2006, Pringle \& Wares 2007), and as a result it is an important consideration for marine management (Botsford et al. 2003, 2009, Gaines et al. 2003). However, characterizing patterns of larval connectivity remains a major challenge for marine ecologists and fisheries scientists (Armsworth 2002, Kinlan \& Gaines 2003, Siegel et al. 2003, 2008, Cowen et al. 2006, Cowen \& Sponaugle 2008).

Empirically, it is virtually impossible to capture the full range of spatial and temporal variability in larval connectivity (Gawarkiewicz et al. 2007, Botsford et al. 2009). Direct methods for assessing larval dispersal are 
hindered by the small size and low concentrations of larvae in the open ocean, while indirect approaches, such as microchemical (e.g. Zacherl 2005) and genetic methods (e.g. Palumbi 2003, Selkoe et al. 2008), have only just begun to adequately describe the site-to-site connectivity necessary for management (e.g. Planes et al. 2009). As a result, modeling approaches have grown in prominence (for recent reviews see Gallego et al. 2007 and Cowen \& Sponaugle 2008).

The goal of this paper is to explore, using simulation approaches, the causes of spatial patterns in larval connectivity for the Southern California Bight (SCB). To do so, we define 2 measures of connectivity: potential and realized larval connectivity. Potential connectivity is defined as the probability of larval transport from a spawning site $(j)$ to a destination location (i), and realized connectivity is defined as the number of larvae that travel from $j$ to $i$. Both are quantified for a given spawning period and pelagic larval duration. Realized connectivity is a function of not only potential connectivity but other factors such as larval production and mortality. Here, realized larval connectivity $\left(L_{j i}\right)$ is defined as the product of potential larval connectivity $\left(W_{j i}\right)$ and larval production $\left(p_{j}\right)$, or

$$
L_{j i}=p_{j} W_{j i}
$$

Both the terms 'connectivity matrix' and 'dispersal matrix' have been used to describe potential connectivity (e.g. Cowen et al. 2006, Baums et al. 2006, Botsford et al. 2009). However, we have adopted the term potential connectivity to emphasize the fact that this quantity does not necessitate actual dispersal, merely the probability that it will occur given larval production.

The SCB is one of the most intensively studied coastal regions of the world (Sverdrup 1941, Hickey 1992, Di Lorenzo 2003, Mitarai et al. 2009). The domain is atypical of the west coast of North America in that the coastline is concave in shape with 8 major islands (see Fig. 1). Surface flows of the SCB are characterized by the equatorward, offshore California Current and recirculation in the form of a poleward, nearshore current. The islands serve to increase the complexity of ocean flow in the SCB (Dong \& McWilliams 2007, Dong et al. 2009), and mesoscale features, such as persistent eddies in the Santa Barbara Channel, have been shown to effect the spatial distribution of larvae (Nishimoto \& Washburn 2002). Ocean circulation patterns change with climate oscillations, such as El Niño and La Niña events (Lynn \& Bograd 2002), with possible consequences for larval connectivity patterns (e.g. Cowen 1985, Selkoe et al. 2007). While the synoptic circulation patterns and dispersal scales within the SCB have been characterized, detailed quantification of site-to-site larval connectivity has yet to be made.

Here, Lagrangian particle simulation methods (Mitarai et al. 2009) have been used to capture the effects of the SCB's complex ocean circulation on potential larval connectivity. This approach uses the velocity fields of a high resolution $(1 \mathrm{~km})$ Regional Ocean Modeling System (ROMS) solution for the SCB (Dong \& McWilliams 2007, Dong et al. 2009) to advect packets of water (Lagrangian particles) that have been parameterized to resemble particular marine species larvae. With this approach, estimates of potential connectivity were made for 3 SCB species: kelp bass Paralabrax clathratus, kelp rockfish Sebastes atrovirens, and red abalone Haliotis rufescens. The larval stages of these 3 species span a range of dispersal characteristics (i.e. spawning period, spawning location, and pelagic larval duration; Table 1) and draw contrasts in their potential and realized larval connectivity patterns. Lagrangian simulations of larval dispersal have been used to quantify potential larval connectivity in various marine systems, for example, in the Caribbean (e.g. Paris \& Cowen 2004, Paris et al. 2005, Cowen et al. 2006), the California Central coast (e.g. PfeifferHerbert et al. 2007), the Atlantic (e.g. Bonhommeau et al. 2009), the southern part of the SCB (e.g. Rasmussen et al. 2009), and the Western Pacific (e.g. Kim et al. 2007, Kimura et al. 1999). However, as it is defined here, realized larval connectivity is not simply potential connectivity but accounts for spatial patterns of larval production.

Accurate descriptions of both potential and realized larval connectivity are important for marine management, e.g., in the design of marine protected area (MPA) networks (e.g. Botsford et al. 2009, Cudney-

Table 1. Species to be modeled and key dispersal parameters. SCB: Southern California Bight

\begin{tabular}{|c|c|c|c|c|}
\hline Common name & Species name & $\begin{array}{l}\text { Upper limit to pelagic } \\
\text { larval duration (d) }\end{array}$ & $\begin{array}{l}\text { Spawning period for } \\
\text { the present study }\end{array}$ & $\begin{array}{l}\text { Primary spawning } \\
\text { areas }\end{array}$ \\
\hline Kelp bass & Paralabrax clathratus & 30 & $\begin{array}{l}\text { June-July (summer) } \\
\text { Sept-Oct (fall) }\end{array}$ & Throughout the SCB \\
\hline Kelp rockfish & Sebastes atrovirens & 60 & June-July (summer) & Northwest SCB \\
\hline Red abalone & Haliotis rufescens & 12 & Year round & Not estimated \\
\hline
\end{tabular}


Bueno et al. 2009). Our approach produces estimates of potential and realized connectivity at spatial and temporal scales that match the needs of spatial fisheries and conservation management, and we conclude with a discussion on ways in which our results can be used to inform management decisions and policy actions.

\section{METHODS}

Simulated species. The kelp bass Paralabrax clathratus is a warm-temperate serranid found predominantly from Point Conception to Punta Abreojos along the west coast of North America (Young 1963, Miller \& Lea 1976, Love 1991). Kelp bass are common inhabitants of the SCB's mainland and island rocky reefs and constitute one of the most important recreational fisheries in the region. Kelp bass spawn from the late spring to early fall (Erisman \& Allen 2006), and their larvae spend approximately $30 \mathrm{~d}$ dispersing with ocean currents (Findlay \& Allen 2002, Shima \& Findlay 2002). Settling kelp bass larvae are most often observed in the upper 5 to $7 \mathrm{~m}$ of the water column (Findlay \& Allen 2002), suggesting that larval depths are predominantly found near the sea surface.

The kelp rockfish Sebastes atrovirens is a cold-temperate member of the family Scorpaenidae and is both commercially and recreationally fished in the SCB. Kelp rockfish ranges from Northern California to Baja California, and adults occupy habitats similar to those of the kelp bass, nearshore rocky reefs and kelp forests (Miller \& Lea 1976, Love 1991). Females release feeding larvae from late winter through the summer (Gilbert-Horvath et al. 2006). Kelp rockfish larvae spend approximately $60 \mathrm{~d}$ dispersing with ocean currents (Romero 1988). Young-of-the-year are observed typically in the kelp forest canopy (Nelson 2001), suggesting that larval depths are typically near the surface.

The red abalone Haliotis rufescens is an ecologically important marine gastropod, and at present there is no fishery in the SCB. Red abalone are associated with rocky kelp habitat ranging from Oregon to Baja California, are found from the intertidal zone to the shallow subtidal zone, and are restricted to upwelling locations along the mainland and the northwestern Channel Islands (Rogers-Bennett et al. 2002). In the SCB, red abalone are thought to spawn year-round, and their larvae have a relatively short pelagic larval duration of $\sim 12$ d (Haaker et al. 2001). Red abalone are known to exhibit negative geotaxis (Leighton 1974); hence, larval depths are likely associated with ocean currents at the sea surface.

To simulate potential larval connectivity, single values (instead of a range) were chosen for pelagic larval durations: $30 \mathrm{~d}$ (kelp bass), $60 \mathrm{~d}$ (kelp rockfish), and
$12 \mathrm{~d}$ (red abalone). Although kelp rockfish primarily spawn in the spring months, we compared its late spawning months of June and July with the same spawning months for kelp bass. This was done to compare connectivity patterns for those fish that spawn at the same time but that have different pelagic larval durations. We used the summer (June, July) and fall (September, October) spawning months of kelp bass to draw comparisons between fish that have the same pelagic larval duration but that spawn at different times.

The nearshore region of the SCB was divided into 135 discrete circular sites of diameter $10 \mathrm{~km}$, whose centers are $5 \mathrm{~km}$ from the shore and are separated roughly $10 \mathrm{~km}$ apart (Fig. 1). Sites 1 to 62 are along the mainland, Sites 63 to 96 are on the Northern Channel Islands (San Miguel, Santa Rosa, Santa Cruz, and Anacapa), and Sites 97 to 135 are on the shore of the Southern Channel Islands (Santa Catalina, San Clemente, San Nicolas, and Santa Barbara; see Fig. 1 for locations). It was assumed that adult red abalone, kelp bass, and kelp rockfish reside within these areas and that there is no adult movement between them (Lowe and Bray 2006). Red abalone is known to be sedentary, with an adult home range well within the scale of the nearshore sites (Rogers-Bennett et al. 2002). Kelp bass home range sizes are smaller than the scale of the nearshore sites (Lowe et al. 2003), while the home range size for kelp rockfish is not well known. Other similar rockfish species have small home range sizes relative to size of the nearshore sites (Lowe and Bray 2006).

Ocean circulation simulations. Solutions from a 3dimensional numerical hydrodynamic model (ROMS; Shchepetkin \& McWilliams 2005) of the SCB were used to advect Lagrangian particles for the period 1996 through 2002. ROMS solves the incompressible, hydrostatic, primitive-equation model with free surface, horizontal curvilinear coordinates. The model's domain is discretized with a grid spacing of $1 \mathrm{~km}$ horizontally and 40 levels vertically, and all 8 islands in the SCB are resolved (Fig. 1). The ROMS solution uses a 3-level nested grid: (1) an outer domain covering the entire US west coast, at $20 \mathrm{~km}$ horizontal grid spacing; (2) a second embedded domain for a larger SCB area, with a $6.7 \mathrm{~km}$ grid resolution; and (3) the finest embedded grid, used in the present study, which has a $1 \mathrm{~km}$ horizontal grid resolution. The lateral open-boundary conditions for the outer grid come from monthly global oceanic reanalysis products (Carton et al. 2000a, 2000b). No-slip wall boundary conditions are applied around the islands, mainland coasts, and the model bottom. A reanalyzed wind with a horizontal resolution of $2 \mathrm{~km}$ was used as the surface forcing, along with climatological heat and freshwater fluxes. The reader is 


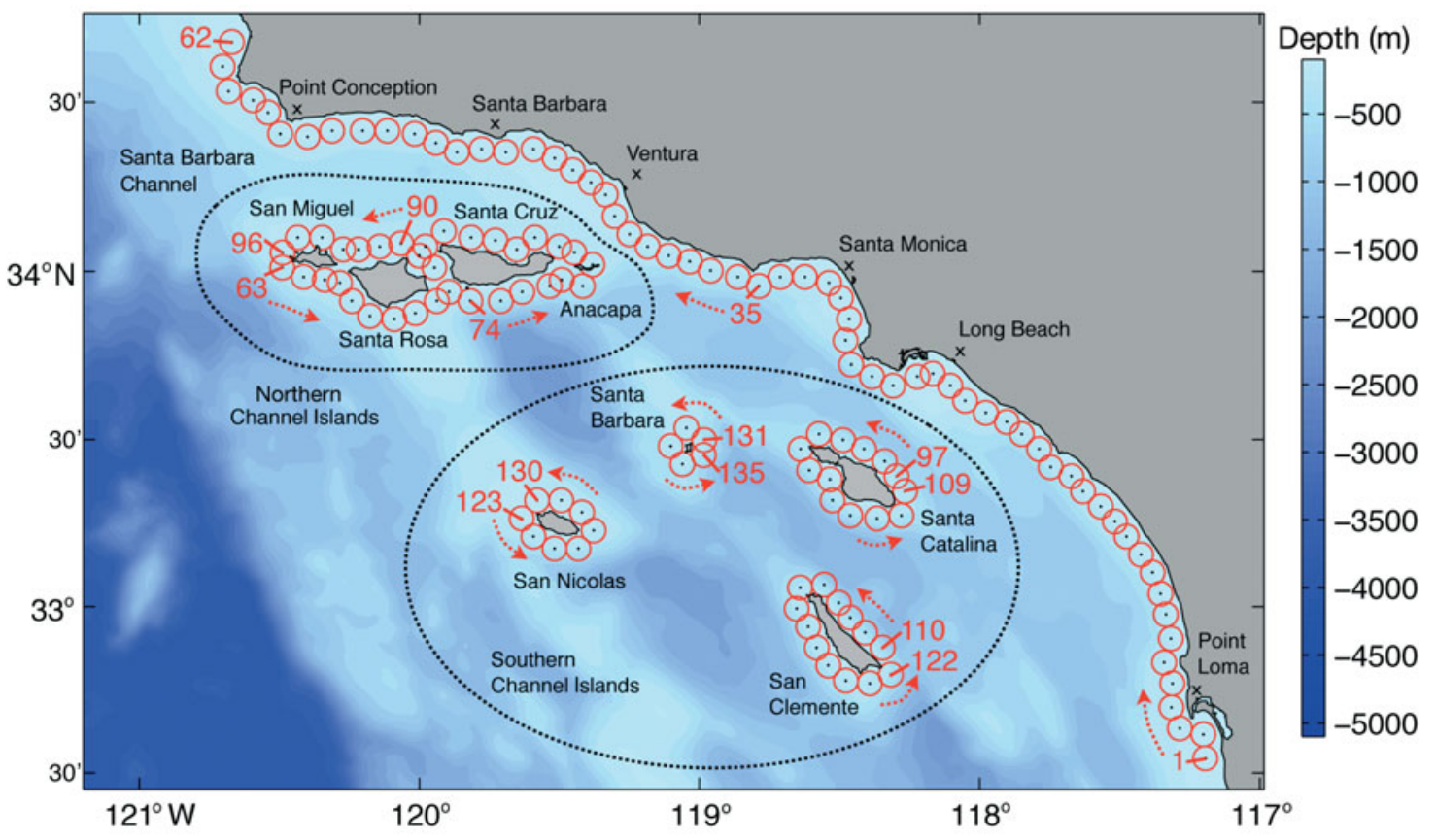

Fig. 1. The Southern California Bight (SCB) with bathymetry from the ocean circulation model. Nearshore site locations and numbers are shown in red. Sites are $5 \mathrm{~km}$ in radius. Names of coastal areas and the $8 \mathrm{SCB}$ islands are also given. Two regions (the Northern Channel Islands and the Southern Channel Islands) are enclosed by dotted black lines

referred to Dong \& McWilliams (2007), Dong et al. (2007) and Dong et al. (2009) for further information on the hydrodynamic model and its validation against oceanographic observations.

Potential connectivity. Potential larval connectivity $\left(W_{j i}\right)$ was determined using the method of Mitarai et al. (2009) (Fig. 2). This method tracks parcels of water, released from a given nearshore site (spawning location, Fig. 1), for a given time (pelagic larval duration), over a given release duration (spawning period) as they advect with ocean velocities provided by the SCB ocean circulation simulations. Larvae are assumed to advect as passive particles; given the vertical positioning of larvae as noted above, this is not an unreasonable assumption for the larvae of kelp bass, kelp rockfish, and red abalone. Lagrangian probability density functions (PDFs; Mitarai et al. 2009) were then used to calculate site-to-site potential larval connectivity from
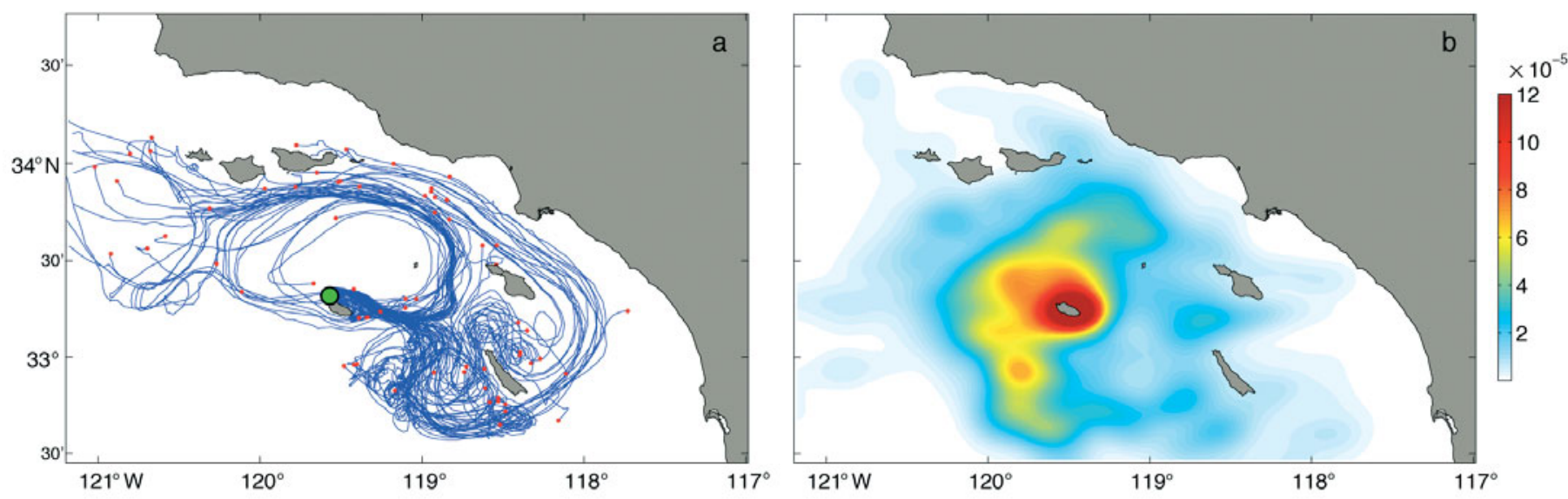

Fig. 2. (a) Example of $30 \mathrm{~d}$, simulated, Lagrangian particle trajectories. Particles were released within the area identified by the green circle on the north shore of San Nicolas Island on 1 January 1996. Particle locations $30 \mathrm{~d}$ after passive advection by ocean currents are identified by red dots. (b) Example of a Lagrangian probability density function (PDF) for the same release location, using $10 \mathrm{~d}$ trajectories. All particles were released on January 1 of each year (1996-2002) and were averaged over the entire period. Colors correspond to probabilities. For details on the Lagrangian PDF method, see Mitarai et al. (2009) 
the individual trajectories (Fig. 2). Potential connectivity matrices are then calculated (Fig. 3) by averaging over 7 yr of simulations (from 1996 to 2002). Individual years allowed the investigation of inter-annual differences and the comparison of connectivity created under El Niño and La Niña conditions. The reader is referred to Mitarai et al. (2009) for a detailed description of the Lagrangian PDF approach and its application to the SCB.

To quantify and visualize potential larval connectivity, partial summation metrics were employed. The following partial summation provides a score of the potential source strength of each site,

$$
W_{j}=\sum_{i \in I} W_{j i}, \quad I=\{1,2, \ldots, 135\}
$$

where $w_{j}$ is the probability that a larva spawned at a particular nearshore site $j$ will disperse with ocean currents to any nearshore site, given the spawning season and pelagic larval duration. $I$ is the set of nearshore sites, 135 in total. A similar method can be employed to quantify the potential destination strength of each site,

$$
W_{i}=\sum_{j \in J} W_{j i}, \quad J=\{1,2, \ldots, 135\}
$$

where $w_{i}$ is a cumulative score of a site's ability to have larvae delivered to it and $J$ is the set of nearshore sites.

Spatial modeling of fecundity and larval production. Estimates of kelp bass and kelp rockfish egg production were made using empirical size and density data collected from an underwater visual census in 2004, at 71 sites in the SCB (the Cooperative Research and Assessment of Nearshore Ecosystems program [CRANE]; for data and methods see www.dfg.ca.gov/marine). Using published estimates of size-specific fecundity and size at maturity for kelp bass (DeMartini 1987) and kelp rockfish (Romero 1988), the egg production for these species was calculated (number of eggs produced $\mathrm{m}^{-2}$ ). These values were then linearly interpolated to the SCB sites defined in this analysis. The interpolated

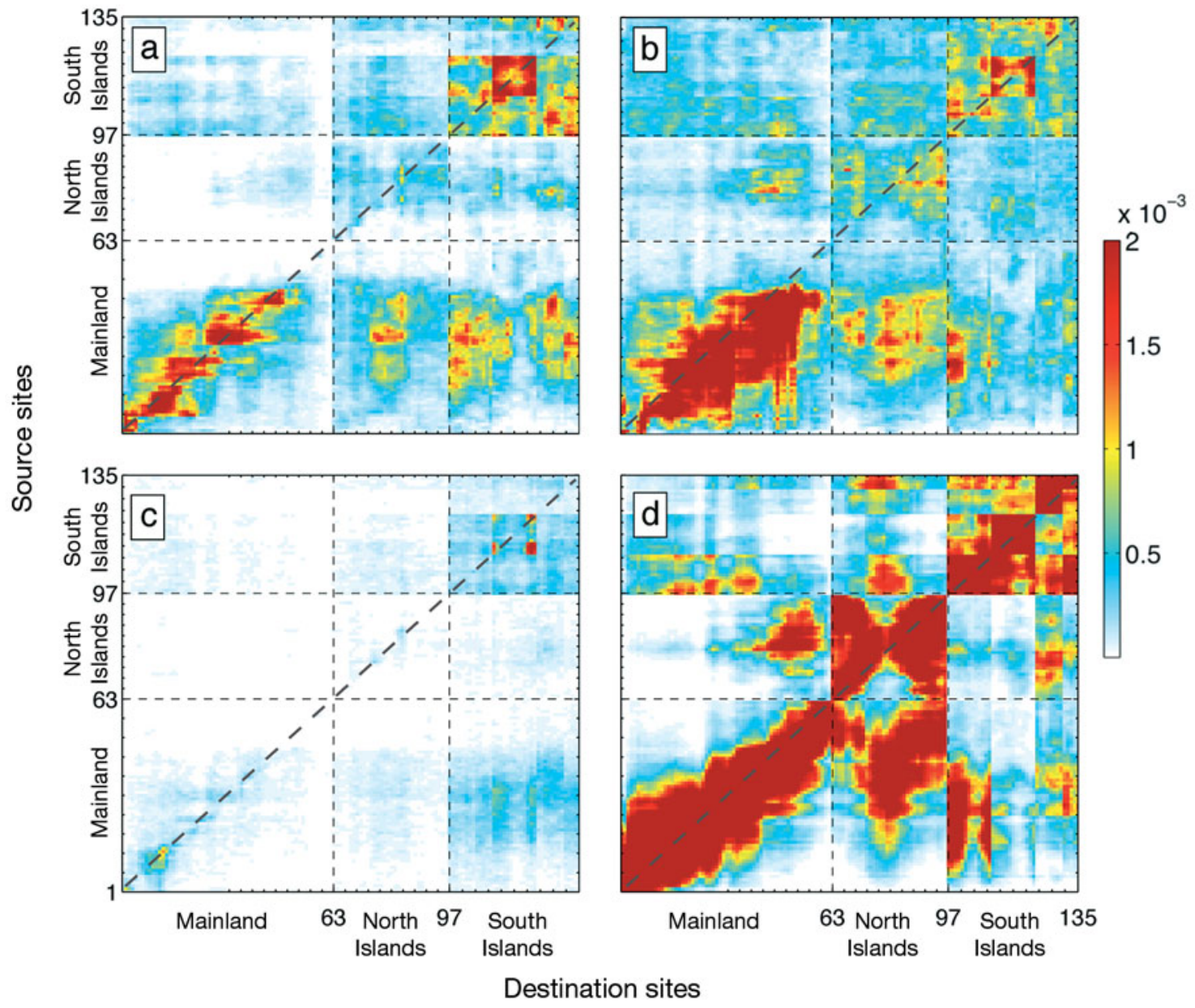

Fig. 3. Potential connectivity matrices ( $\left.W_{j i}\right)$ for (a) summer spawning kelp bass, (b) fall spawning kelp bass, (c) summer spawning kelp rockfish, and (d) red abalone. Elements of each matrix correspond to probabilities of larval transport from a given source site ( $j$, the vertical axis) to a given destination site ( $i$, the horizontal axis). 
areal egg production rates were then multiplied by the area of suitable habitat, in this case the area of rocky substrate (Clark et al. 2005), to estimate larval production over the entire area of each simulation site.

Realized connectivity. Estimates of realized larval connectivity were made by multiplying potential connectivity with values of egg production (Eq. 1). These values were then standardized by the total number of larvae that successfully connect nearshore populations $\left(\Sigma_{j} \Sigma_{i} L_{j i}\right)$. Normalizing values of realized connectivity by the total larval output focuses discussion on the spatial patterns of realized connectivity rather than absolute values. This is essential given that larval mortality is unknown and will likely change the absolute value of realized connectivity. Like estimates of potential connectivity, values of realized larval connectivity are in matrix form.

Partial summation metrics are employed to quantify realized larval connectivity. The following partial summation provides a score of the realized source strength of each site,

$$
l_{j}=\sum_{i \in I} L_{j i}, \quad I=\{1,2, \ldots, 135\}
$$

where $l_{j}$ is the fraction of the total number of dispersing larvae (between all sites $I$ ) that are spawned at a given source site $j$, given the spawning season and pelagic larval duration. A similar method can be employed to quantify the realized destination strength of each site,

$$
l_{i}=\sum_{j \in J} L_{j i}, \quad J=\{1,2, \ldots, 135\}
$$

where $l_{i}$ is the fraction of the total number of dispersing larvae (between all sites $J$ ) that are delivered to a given destination site, $i$. Several terms have been used to describe realized destination strength $\left(l_{i}\right)$, including larval delivery and larval settlement.

We analyzed the relationship between larval production $\left(p_{j}\right)$ and realized destination strength $\left(l_{i}\right)$ and also the relationship between potential $\left(w_{i}\right)$ and realized destination strength $\left(l_{i}\right)$. The former provides insight into post-settlement processes such as densitydependent mortality, and the latter quantifies the importance of ocean circulation in directing larval dispersal patterns. In order to test the strength of the relationship between potential and realized destination strength, the spatial distribution of larval production was reorganized through random permutations, and resulting Pearson correlation coefficients, between potential and realized destination strengths, were recorded. Using the potential connectivity matrices that correspond to the years 1997 and 1999, the effects of El Niño and La Niña ocean conditions on realized larval connectivity were also investigated. This last analysis assumes constant larval production.

\section{RESULTS}

\section{Potential connectivity}

Across species, there are 3 noticeable patterns in the long-term mean potential connectivity distributions $\left(W_{j i}\right.$, Fig. 3). First, the magnitude of connectivity differs. Red abalone potential connectivity levels are higher than those for kelp bass (both spawning seasons), whose values are higher than those for kelp rockfish (Fig. 3). This is because the probability of returning to the nearshore diminishes as the pelagic larval duration increases. Pelagic larval duration values for kelp rockfish, kelp bass, and red abalone are $60 \mathrm{~d}, 30 \mathrm{~d}$, and $12 \mathrm{~d}$, respectively.

Second, the potential connectivity matrices are asymmetric. For example, the matrices for summer and fall spawning kelp bass (Fig. 3a,b) show connections from mainland sites (Sites 1 to 62) to the Channel Island sites (Sites 63 to 135) but not in the other direction. The patterns of asymmetry change with species. Red abalone shows strong symmetry close to the diagonal of its potential connectivity matrix. The short pelagic larval duration of red abalone does not allow long dispersal distances; therefore, the mainland/ island asymmetry found in kelp bass is less apparent in red abalone potential connectivity estimates.

Lastly, the signal of self-connectivity is observed through high values on the diagonal of the matrices. This is most evident for red abalone whose larval connections are highly clustered around the diagonal. This, again, is a function of pelagic larval duration. Shorter pelagic larval durations produce smaller dispersal distances and hence stronger connectivity to sites near and including the source.

The partial summation metric, $w_{j}$, describes the number of successful potential larval connections produced from each source location (Fig. 4). For all species, summer spawning kelp bass (Fig. 4a), fall spawning kelp bass (Fig. 4b), summer spawning kelp rockfish (Fig. 4c), and red abalone (Fig. 4d), the sites in the center of the domain, from Ventura to south of Long Beach, provide the strongest potential sources. Interestingly, summer spawning kelp bass (Fig. 4a) and kelp rockfish (Fig. 4c) both have strong sources on Santa Catalina and San Clemente Islands even with differences in their pelagic larval duration. This is not the case for fall spawning kelp bass (Fig. 4b) and red abalone (Fig. 4d) whose strong potential destinations are only on the mainland.

There are also distinct differences between cases in potential destination strength ( $w_{i}$, Fig. 5). For example, summer spawning kelp bass have strong destinations on the Southern Channel Islands (San Clemente, San Nicolas, Santa Barbara, and Santa Catalina; Fig. 5a), 

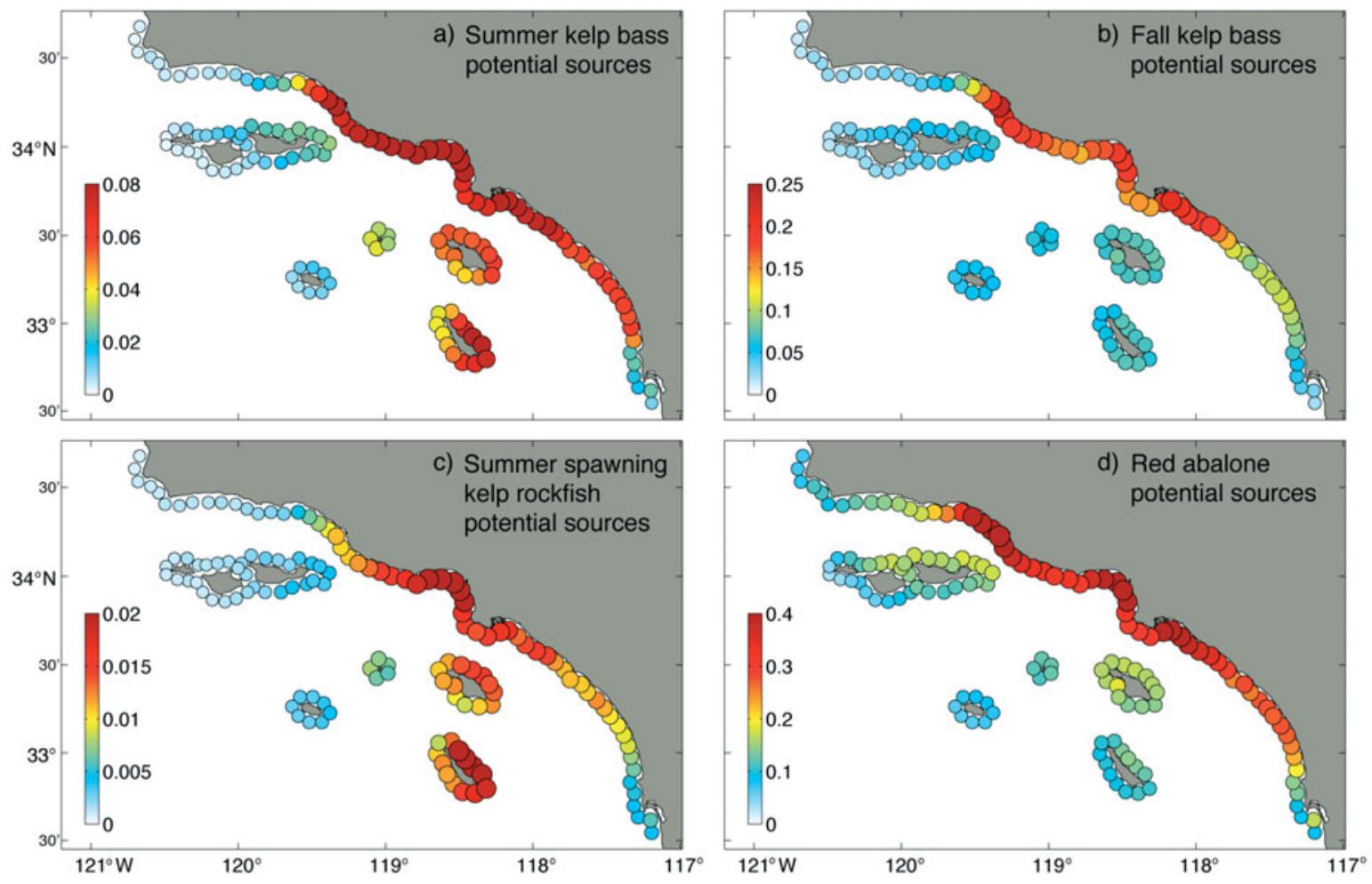

Fig. 4. Potential source strength $\left(w_{j}\right)$ for (a) summer spawning kelp bass, (b) fall spawning kelp bass, (c) summer spawning kelp rockfish, and (d) red abalone. The area and color of a particular site reflect its potential source strength
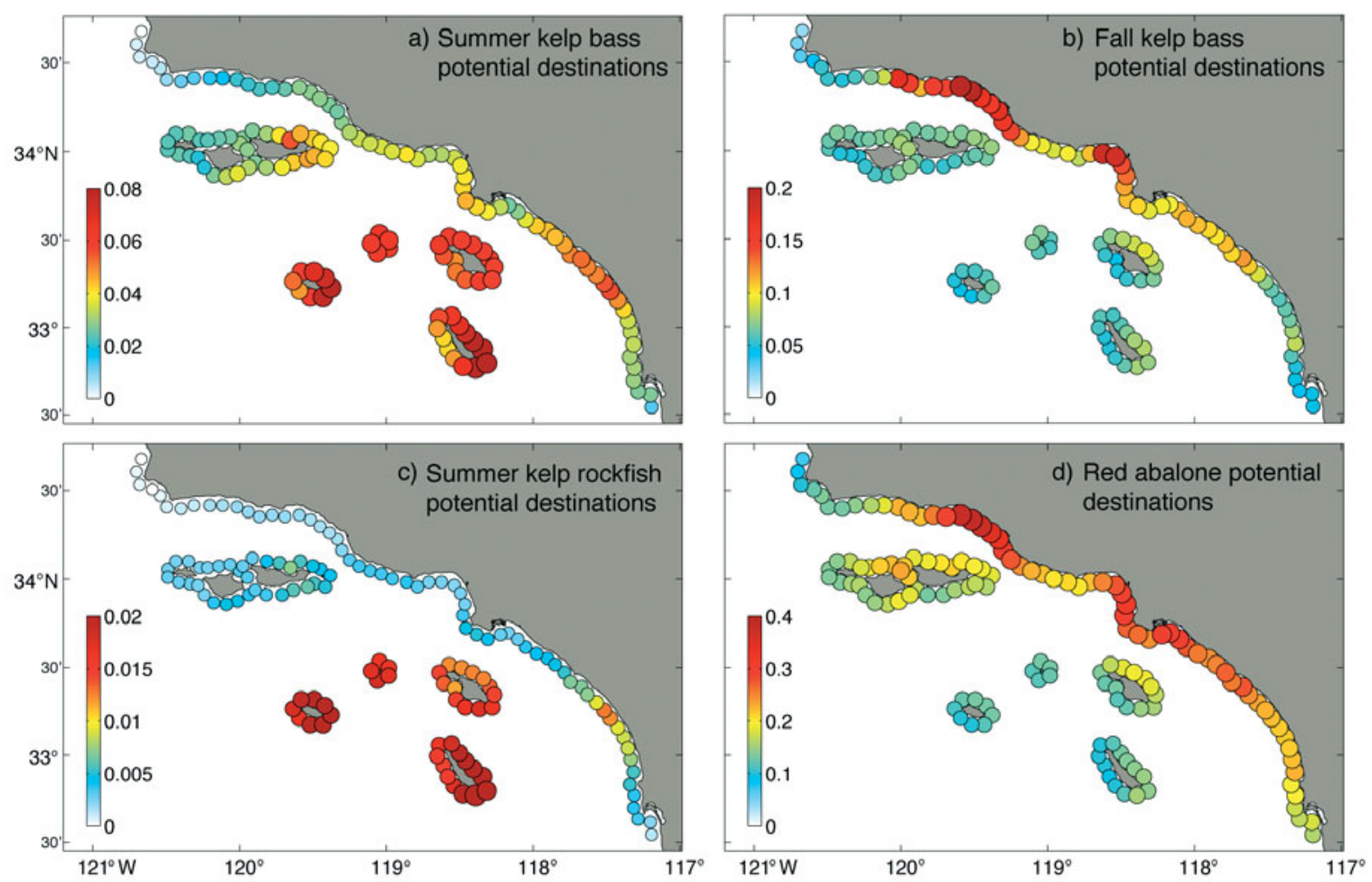

Fig. 5. Potential destination strength $\left(w_{i}\right)$ for (a) summer spawning kelp bass, (b) fall spawning kelp bass, (c) summer spawning kelp rockfish, and (d) red abalone. The area and color of a particular site reflect its potential destination strength 
whereas in the fall spawning season, mainland sites in the Santa Barbara Channel and Santa Monica Bay receive the most potential connections (Fig. 5b). Strong destinations of summer spawning kelp rockfish show patterns similar to those of summer spawning kelp bass and can be found on the Southern Channel Islands (Fig. 5c). Strong red abalone destinations (Fig. $5 \mathrm{~d})$ are found along the mainland and the Northern Channel Islands (Anacapa, Santa Rosa, Santa Cruz, San Miguel). The various high-value potential sources have different primary destinations. For example, strong mainland sources for summer spawning kelp bass make potential connections to the Southern Channel Islands. However, the reverse is not true. Strong Southern Channel Island sources do not make strong potential connections to the mainland. This asymmetry in potential connectivity is also evident for red abalone and summer spawning kelp rockfish.

\section{Modeled fecundity and larval production}

The spatial distribution of kelp bass and kelp rockfish egg production shows striking differences (Fig. 6). Modeled kelp bass egg production is highest on the south of Santa Catalina Island, with other notable areas north of Point Loma and on San Clemente Island, the mainland sites in the Santa Barbara Channel, and the northern sites of the Northern Channel Islands (Fig. 6c). There is virtually no kelp bass egg production north of Point Conception and in the west of the Santa Barbara Channel; it is also minimal along the mainland around the Los Angeles area where there is relatively little suitable habitat.

Kelp rockfish egg production is highest at the western sites of the Northern Channel Islands, mainland sites north of Point Conception, and at sites on San Nicolas Island (Fig. 6d). Most mainland and other southern SCB Islands (Santa Catalina, San Clemente, and Santa Barbara) show minimal to zero larval production.

\section{Realized connectivity}

Realized connectivity matrices (Fig. 7a,b) are more sparse than potential connectivity matrices, a result of sites with low or zero larval productivity. For example, for both kelp bass and kelp rockfish there are significant potential connections from the mainland sites.
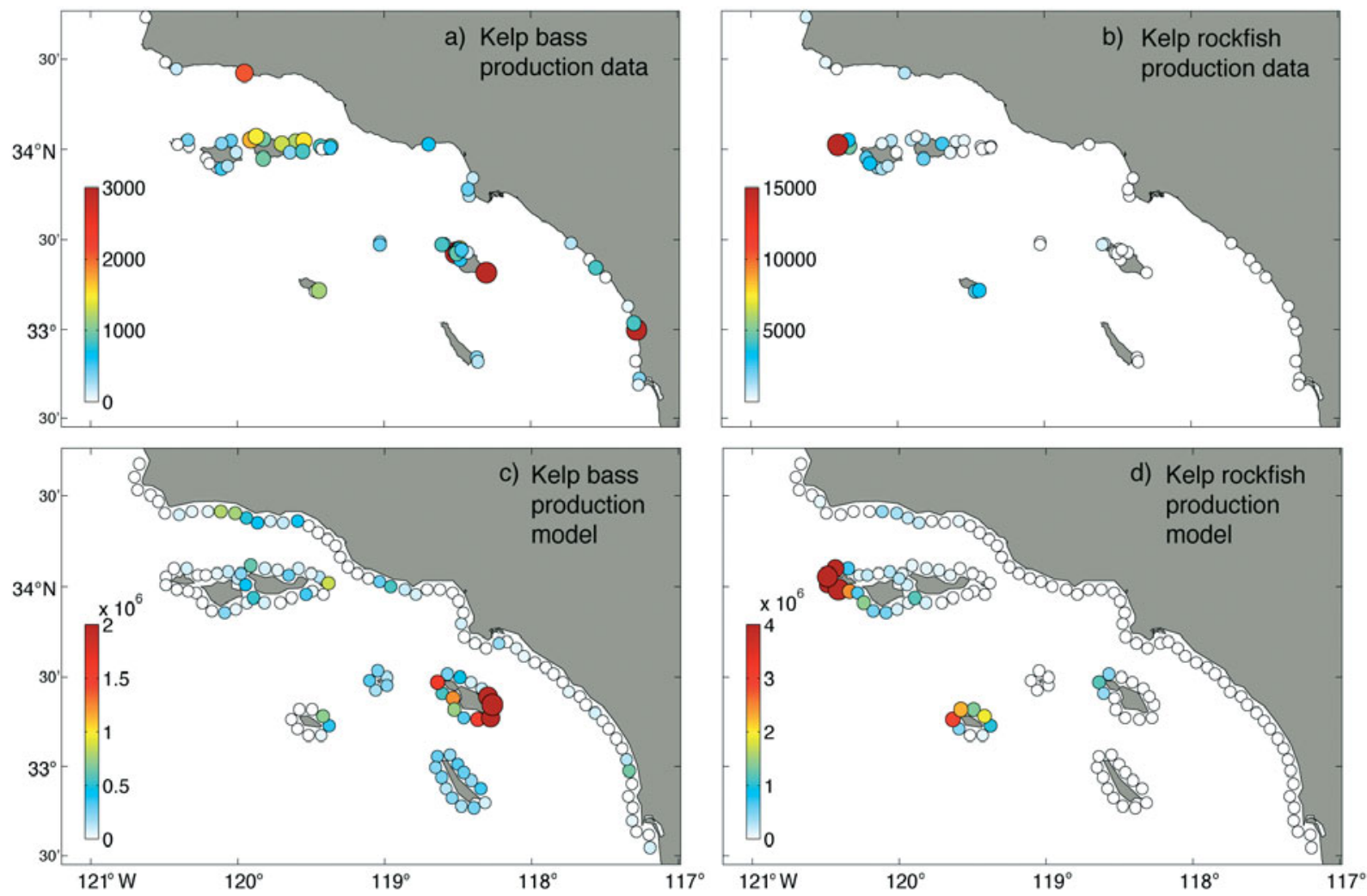

Fig. 6. Empirical estimates of (a) kelp bass and (b) kelp rockfish egg production at the CRANE empirical survey sites. Values are then linearly interpolated and scaled by the area of rocky substrate, resulting in larval production $\left(p_{j}\right)$ for (c) kelp bass and (d) kelp rockfish. The size and color of the circles reflect egg production values. Larval production is assumed to scale with egg production 

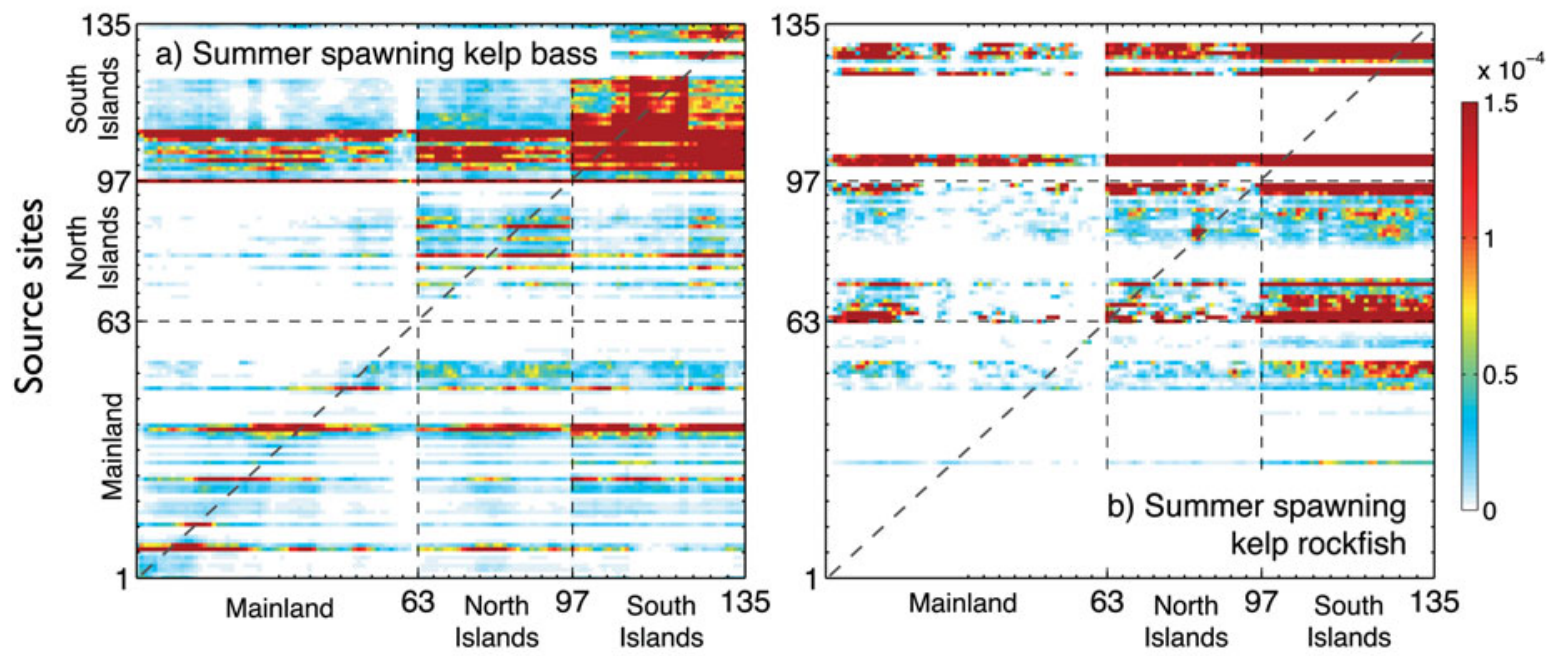

Destination sites

Fig. 7. Realized connectivity matrices ( $L_{j i}$ ) for (a) summer spawning kelp bass and (b) summer spawning kelp rockfish. Values of realized larval connectivity are standardized by the matrix summation $\Sigma_{j} \Sigma_{i} L_{j i i}$ hence, the units of realized connectivity are fractions of the total number of dispersing larvae

However, the whole of the southern part of the SCB is typified by zero kelp rockfish larval productivity (Fig. 6d) and low kelp bass larval productivity (Fig. 6c). As a result, large numbers of potential larval connections from these mainland sites (Sites 1 to 63) have zero realized connections (Fig. 7a,b).

Realized source strength $\left(l_{j}\right)$ for kelp bass (summer and fall spawning) and summer spawning kelp rockfish (Fig. 8a,b, and 8c, respectively) reflect, to first order, the spatial patterns in their larval production (Fig. 6c,d). The strongest realized source, for summer and fall spawning kelp bass, are sites on the south of Santa Catalina Island. Secondary source sites (light blue) are then found on the northern side of the Santa Barbara Channel, the eastern sites on the Northern Channel Islands, and San Clemente Island (Fig. 8a,b). Realized source locations for kelp rockfish larval connectivity (Fig. 8c) occur on San Nicolas Island, the north side of Santa Catalina Island, and the western sites of San Miguel Island. In contrast to their potential source strength, the sites in the Santa Monica Bay have minimal realized source strength. This is due to very low larval productivity in this region.

Strong realized larval destinations $\left(l_{i}\right)$ of summer spawning kelp bass (Fig. 8d) occur on the Southern Channel Islands (San Clemente, San Nicolas, Santa Catalina, and Santa Barbara). For fall spawning kelp bass, strong destinations occur throughout the SCB (Fig. 8e). For both kelp bass spawning periods, there are few sites with very low destination strengths. Comparing the destination and source strength patterns indicates that a few spawning locations can effectively seed the whole domain with larvae. Like those of summer spawning kelp bass, summer spawning kelp rockfish's realized destinations are primarily on the Southern Channel Islands (San Clemente, Santa Catalina, Santa Barbara, and San Nicolas; Fig. 8f). Summer spawning kelp rockfish also shows that a few sites effectively seed the SCB, but now with destinations preferentially for the Southern Channel Islands.

The relationship between larval production $\left(p_{j}\right)$ and realized destination strength $\left(l_{i}\right)$ provides insight into processes that shape the eventual spatial distribution of adults. Larval production should match realized destination strength; locations that have high larval settlement should have high numbers of adults and hence production. However, processes such as density-dependent mortality and environmental or habitat dependencies will create differences between the two. For summer spawning kelp bass and fall spawning kelp bass, weak but significant correspondence is found between larval production and realized destination strength; Pearson correlation coefficient values (r) are 0.41 and 0.42 , respectively $(p<0.01)$. However, for summer spawning kelp rockfish, there was no significant relationship $(r=0.07, p=0.45)$. Strong realized destinations for kelp rockfish are on the Southern Channel Islands (Fig. 8f), locations that have minimal larval production. The disparity between realized destination strength and larval production for kelp rockfish suggests the importance of post-delivery processes. For example, the Southern Channel Islands are strong realized destinations; however, those larvae do not survive to adulthood and contribute to larval pro- 

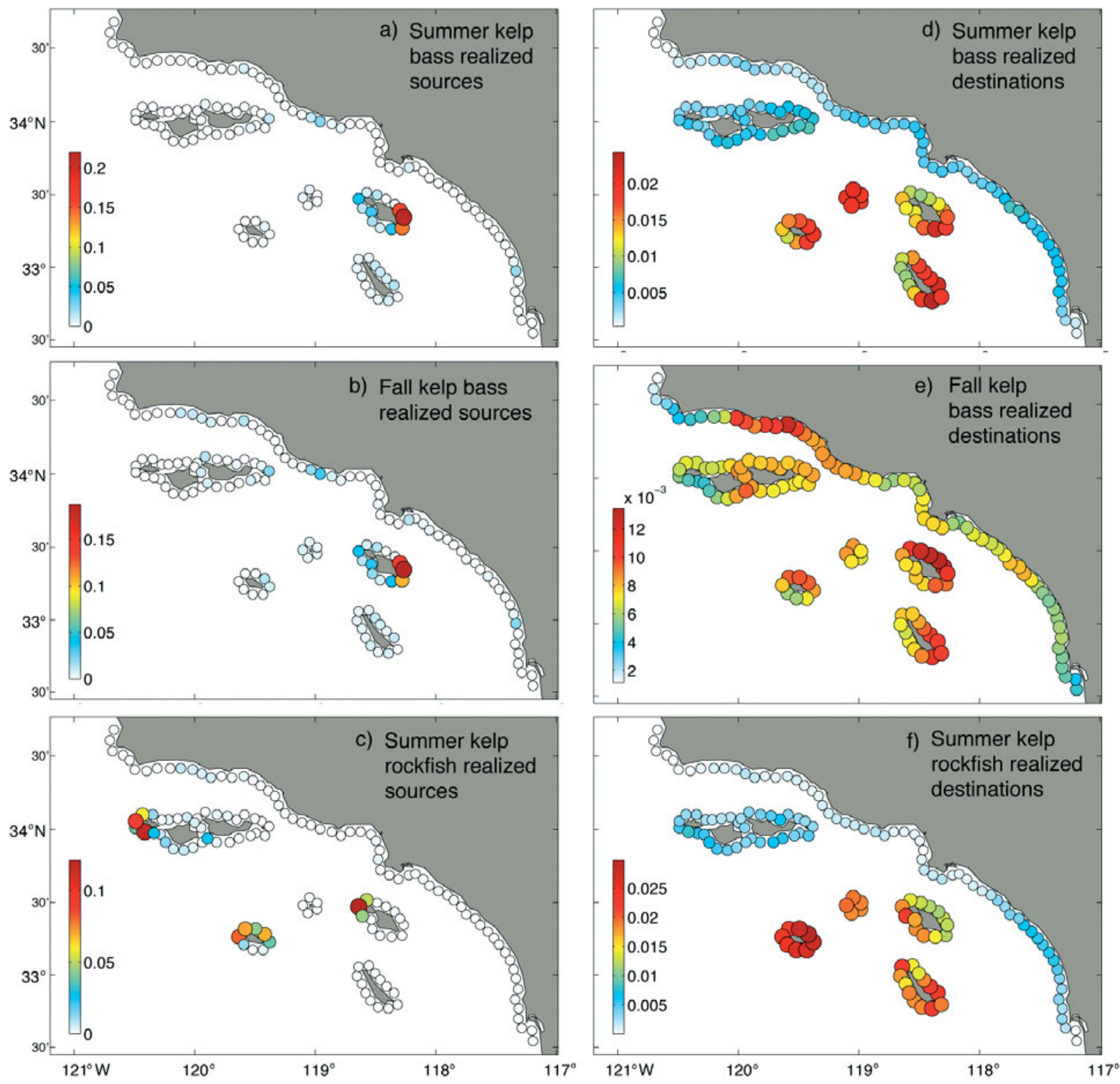

Fig. 8. Realized larval connectivity sources $\left(l_{j}\right)$ for (a) summer spawning kelp bass, (b) fall spawning kelp bass, and (c) summer spawning kelp rockfish. Destinations of realized larval connectivity $\left(l_{i}\right)$ for $(d)$ summer spawning kelp bass, (e) fall spawning kelp bass, and (f) summer kelp rockfish. The area and color of the circles reflect realized source and destination strengths

duction. These results show that in order to quantify population connectivity, and not simply larval connectivity, post-delivery processes must be understood. Dynamic models that explicitly incorporate demographic mechanisms (e.g. Armsworth 2002, Gerber et al. 2003) offer a path by which to link larval and population connectivity.

The relationship between potential destination strength $\left(W_{i}\right)$ and realized destination strength $\left(l_{i}\right)$ was also analyzed. For summer spawning kelp bass and summer spawning kelp rockfish, there is a significant positive relationship between realized and potential destination strength (Fig. 9a,b), with $\mathrm{r}$ values of 0.91 and 0.89 , respectively ( $p<0.01$ in both cases). For the fall spawning kelp bass (Fig. 9c), a significant although weaker linear relationship was still found $(\mathrm{r}=0.42, \mathrm{p}<$ 0.01). Looking deeper, it can be seen that the relationship between potential and realized destination strength is driven by regional connectivity characteristics. For both the summer spawners (kelp bass, Fig. 9a, and kelp rockfish, Fig. 9b), a similar positive, linear relationship between potential and realized destina- 

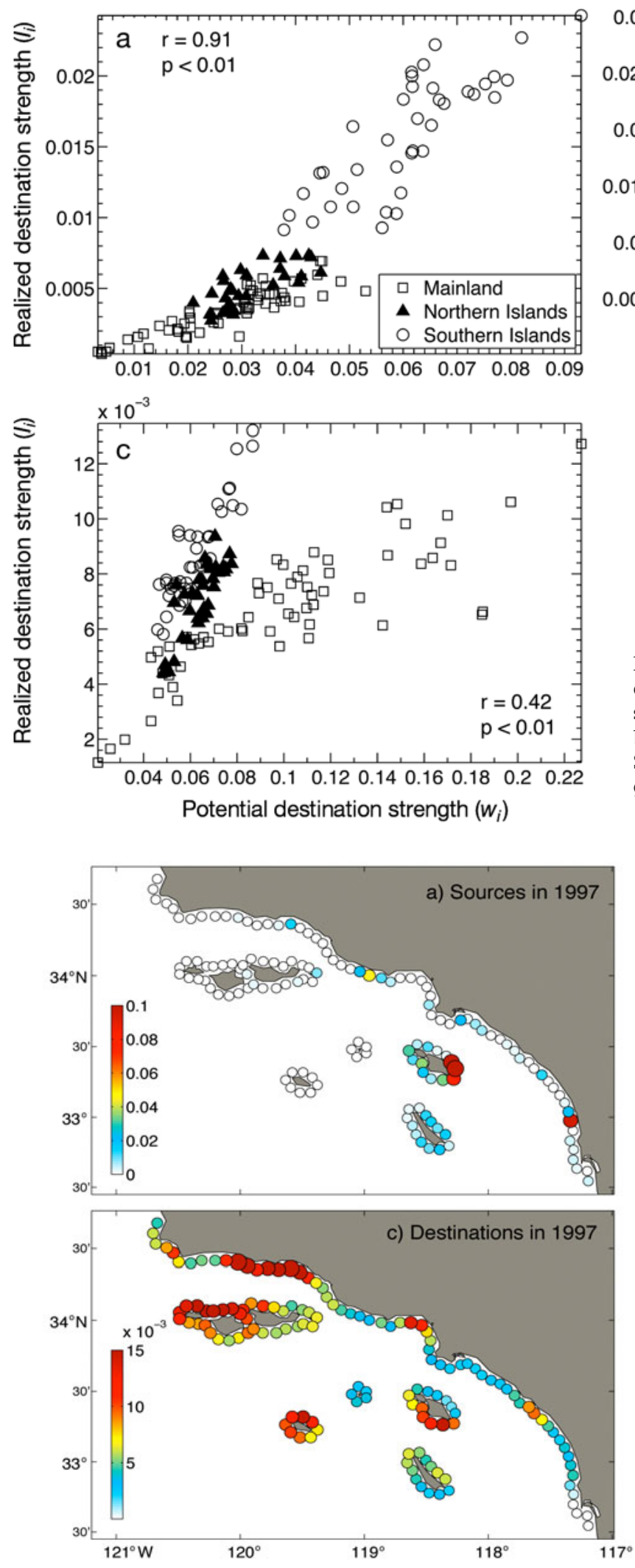

Fig. 9. Realized destination strength as a function of potential destination strength for (a) summer spawning kelp bass, (b) summer spawning kelp rockfish, and (c) fall spawning kelp bass. Symbols show the relationship in different regions of the Southern California Bight. Squares: mainland sites; triangles: Northern Channel Islands; circles: Southern Channel Islands
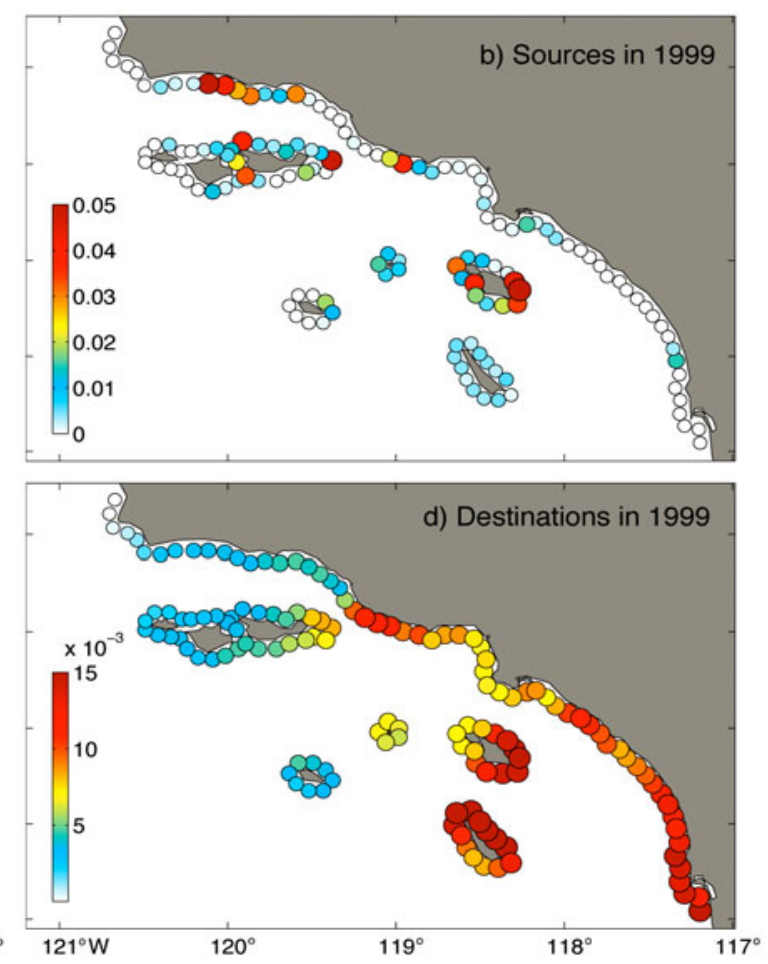

Fig. 10. Sources of realized larval connectivity for fall spawning kelp bass in the years (a) 1997 and (b) 1999. Destinations of realized larval connectivity for fall spawning kelp bass in the years (c) 1997 and (d) 1999. The area and color of the circles reflect realized source and destination strengths 
tion strength was observed on the mainland (squares), the Northern Channel Islands (triangles), and on the Southern Channel Islands (circles). This is contrasted by the fall spawning kelp bass (Fig. 9c) where the slope of the relationship differed among the 3 regions. The strong linear relationship is seen in each region: $\mathrm{r}$ values of $0.81,0.91$, and 0.84 were found for the Northern Channel Islands, Southern Channel Islands, and mainland sites, respectively (all $\mathrm{p}<0.01$ ).

The strong positive relationship between potential and realized destination strength in the summer spawning months is surprising given the distinct spatial heterogeneity in egg production. To investigate this further, the spatial distribution of larval production was randomly reorganized and its effect on the relationship between potential and realized destination strength analyzed. Across all permutations of the spatial distribution of larval production, potential destination strength of both summer spawning kelp bass and kelp rockfish consistently showed high correlation with realized destination strength, with mean $r$ values of 0.87 and 0.95 and standard deviations (SD) of 0.09 and 0.03 , respectively. For fall spawning kelp bass, the different regions of the SCB consistently showed strong positive relationships with mean $\mathrm{r}$ values of 0.88 ( $\mathrm{SD}=0.09$ for all regions). The differences in the relationship between potential and realized destination strength between these regions (mainland, Northern Channel Islands, Southern Channel Islands) were removed through reorganizing the spatial distribution of larval production; this suggests that, in the fall, regional patterns in connectivity are sensitive to larval production. However, because of the consistent positive relationship in each region, realized destination strength is still predominantly directed by potential connectivity.

Inter-annual differences in realized connectivity are also apparent (Fig. 10), at least during times of strong climatic events. During the fall of 1997, a strong El Niño occurred, and realized fall spawning kelp bass sources were strongest on mainland sites north of Point Loma and at sites on the south of Santa Catalina Island (Fig. 10a). During the La Niña conditions of 1999 (Fig. 10b), strong sources still were found on the south shores of Santa Catalina Island, but there are now many realized sources from the Santa Barbara Channel. There is also a contrast in the realized larval destinations; during El Niño conditions (Fig. 10c), northern mainland and island sites serve as a strong destination, with relatively few larvae traveling to the south of the domain. During La Niña conditions in 1999 (Fig. 10d), larvae were transported more to sites in the south of the domain, with few strong destinations in the west of the Santa Barbara Channel.

\section{DISCUSSION}

\section{Larval connectivity characteristics}

It is evident that realized larval connectivity in the SCB is not uniform, with source and destination strengths varying from location to location and from year to year. The reason for such heterogeneity lies in the ocean circulation of the SCB. Larval production, although highly spatially heterogeneous, was shown to have little effect on spatial patterns of realized destination strength, with potential destination strength consistently showing strong correspondence (across species and across random permutations of the spatial distribution of larval production). Given the high spatial heterogeneity in larval production, this result is surprising. We also found that there is correspondence between species; e.g. both kelp bass and kelp rockfish larvae spawned in the summer have strong realized larval destinations on the Southern Channel Islands (Fig. 8d,f). This again is a surprising result given the differences in the spatial distribution of larval production and suggests that the timing of larval spawning has a stronger effect on dispersal patterns than pelagic larval duration. These results strongly suggest that ocean circulation has a dominant role in directing larval settlement patterns.

At the spatial scales of this investigation, the traditional paradigm for larval connectivity has been to assume a larval pool where the spatial distribution of larval delivery is uniform and independent of the spatial distribution of larval production (Vance 1973, Pineda 1994). Although the inadequacies in the larval pool model have been recently noted (e.g. Warner \& Cowen 2002), our results suggest that a modified larval pool model may exist. As in the larval pool model, patterns in larval delivery are decoupled from those of larval production. However, unlike the larval pool model there is spatial heterogeneity in larval delivery. Our results show that realized destination strength is highly heterogeneous with distinct hot spots, challenging the larval pool paradigm. The mechanisms for heterogeneity in realized destination strength are oceanographic and are well explained by potential connectivity.

The connectivity patterns in the present study have been investigated using simple partial summation metrics illustrating source (e.g. Figs. $4 \& 8 a-$ c) and destination (e.g. Figs. 5 \& 8d-f) strengths. This approach quantifies connectivity separately for each species in mapped coordinates; however, it does not provide any information about the bidirectional nature of larval connectivity. Developing statistics that account for the asymmetry in realized larval connectivity will be a great addition to the field, and indeed some steps have 
been taken in this direction (Treml et al. 2008). For example, network analysis has been used to gain insight into the spread of infectious diseases (e.g. May \& Lloyd 2001) and the flow of energy in food webs (e.g. Dunne 2006, Amundsen et al. 2009). Both the potential and realized connectivity matrices can be considered as networks (specifically as weighted and directed networks), and network metrics that account for the asymmetry and non-binary nature of larval connectivity networks may potentially be very informative to spatial management methods (e.g. Urban \& Keitt 2001, Bode et al. 2008, Treml et al. 2008).

\section{Temporal changes in connectivity}

The magnitude and time scales over which larval connectivity varies is extremely important to understanding the demographics of marine species (e.g. Siegel et al. 2008). For some applications, knowledge of larval connectivity on multi-year time scales (as in this study) is appropriate. These include considerations of genetic, physiological, or behavioral adaptations that occur over the time scales of many generations. However, prediction of stock-recruitment dynamics requires knowledge of larval connectivity over annual (or seasonal) time scales.

Intra-annual differences in realized connectivity match well with current knowledge of the circulation patterns of the SCB. This is shown in our analysis of kelp bass' summer and fall spawning seasons. During the fall months there is a strengthening of a mainland poleward flow known as the inshore countercurrent (Di Lorenzo 2003, Mitarai et al. 2009). The Lagrangian simulations capture this circulation feature and create potential and realized larval connectivity patterns from southern mainland sites to northern sites. In contrast, during the summer months flow patterns are typified by a strengthening of the domain scale recirculation feature, the Southern Californian Eddy (Di Lorenzo 2003). As a result, the 4 Southern Channel Islands (Santa Catalina, Santa Cruz, Santa Barbara, and San Nicolas) become strong destinations of potential and realized connectivity (Mitarai et al. 2009). In our analysis it was assumed that larval production remained constant during the El Niño and La Niña periods. This is likely not the case as factors that influence larval production (e.g. ocean temperature, primary production) are known to change during these times. However, as indicated by the results of this study, larval production has a minimal effect on patterns of larval delivery, and as such our analysis is likely to accurately capture changes due to these conditions. Changes in larval production with El Niño and La Niña conditions will likely change the overall magnitude of settlement, but, short of a complete failure in production, the locations to which larvae are delivered are, to first order, a function of potential connectivity patterns.

Patterns in realized larval connectivity also show strong inter-annual variability. Ocean circulation patterns in the SCB, during El Niño years, are characterized by strengthening and broadening of the poleward inshore countercurrent (Fig. 10). In contrast, during La Niña conditions the poleward circulation feature weakens, and there are strong, sustained upwellingfavorable winds resulting in greater off-shore flow (Dever \& Winant 2002, Lynn \& Bograd 2002). Realized larval connectivity patterns of fall spawning kelp bass during the years 1997 (El Niño conditions) and 1999 (La Niña conditions) capture these changes in ocean circulation. In particular, during El Niño conditions, sources of realized connectivity are found mainly in the south of the SCB (Fig. 10a), with realized connections to sites further north and throughout the domain (Fig. 10b). This result matches current thinking that during El Niño conditions recruitment in the SCB comes mainly from the south (e.g. Johnson 1959, Cowen 1985, Pringle 1986, Carr 1994, Moser et al. 2001). Although our domain does not extend beyond the USA/Mexico border, this result suggests that, during El Niño conditions, larvae spawned in Baja Mexico will travel north to the SCB.

Variability at shorter, intra-seasonal time scales represents processes, such as individual spawning events, that match the time scales of eddy-scale flow patterns (typically 2 wk in the SCB; Siegel et al. 2008). Mitarai et al. (2009) show that the intra-seasonal variance of potential connectivity is roughly the same magnitude as the variance for both the inter-annual and seasonal time scales. This highlights the strong influence of ocean eddy motions in directing larval dispersal patterns. Because we averaged potential connectivities over 7 yr and assumed larval production to be constant through time, this signal of intra-seasonal variability is not captured in our analysis. This can be explored further using models of marine species demography (e.g. Neubert \& Caswell 2000, Armsworth 2002, Gerber et al. 2003, Hastings \& Botsford 2006, White 2009) and potential connectivity matrices with higher temporal resolution. Investigating larval connectivity as a timevarying process is the focus of future work.

\section{Application to marine management}

Spatial approaches to fisheries management, such as the design of MPA networks, will benefit from detailed descriptions of larval connectivity (Botsford et al. 2003, Halpern \& Warner 2003, Palumbi 2003, Roberts et al. 2003). Here, we give 2 examples of the use of our mod- 
eling approach to MPA design, quantifying self- and remote connectivity.

One of the central connectivity concepts relevant to marine management is that of an open versus closed population (Roughgarden et al. 1985, Cowen et al. 2000). An open population receives most of its next generation adults from remote locations, whereas closed populations depend upon local sources. Given a realized connectivity matrix, there are 2 metrics that can be used to measure openness/closeness. Comparing the diagonal element of a realized connectivity matrix with the summation of the respective column produces a measure of the fraction of the total number of arriving larvae that were produced locally,

$$
\gamma_{i}=\frac{\operatorname{diag}\left(L_{j i}\right)}{l_{i}}
$$

where $\operatorname{diag}\left(L_{j i}\right)$ are the diagonal elements of the realized connectivity matrix $\left(L_{j i}\right)$ and $l_{i}$ is the realized destination strength metric defined in Eq. (5). $\gamma_{i}$ is a measure of self-delivery, and if $\gamma_{i}$ is high (towards 1 ), then a high proportion of the total number of arriving larvae were produced at that site (i.e. closed). Conversely, if $\gamma_{i}$ is low (towards zero), then a high proportion of the total number of arriving larvae come from remote locations (i.e. open).

The spatial distribution of self-delivery, $\gamma_{i}$, for fall spawning kelp bass is shown in Fig. 11a. Values of $\gamma_{i}$ are low, with a maximum self-connectivity value of $17 \%$ occurring on the southern sites of Santa Catalina Island, suggesting most locations are open. There are, however, significant differences in $\gamma_{i}$ among sites. This suggests that retentive ocean circulation features vary throughout the SCB. For example, sites in the south of the SCB (around Santa Catalina and San Clemente Islands) show relatively high levels of $\gamma_{i}$ (i.e they are more closed relative to other sites). In this area a persistent eddy feature is known to exist (Mitarai et al. 2009), which is likely the cause for higher values of $\gamma_{i}$.

Comparing the diagonal element of a realized connectivity matrix with the summation of the respective row produces a slightly different measure of openness/closeness. This metric defines local retention and is the fraction of larvae produced at a site that then return to that site (Botsford et al. 2009). Mathematically in Eq. (6), the diagonal elements of $L_{j i}$ are now divided by the source strength metric $\left(l_{j}\right)$. For fall spawning kelp bass, local retention is high at several locations on
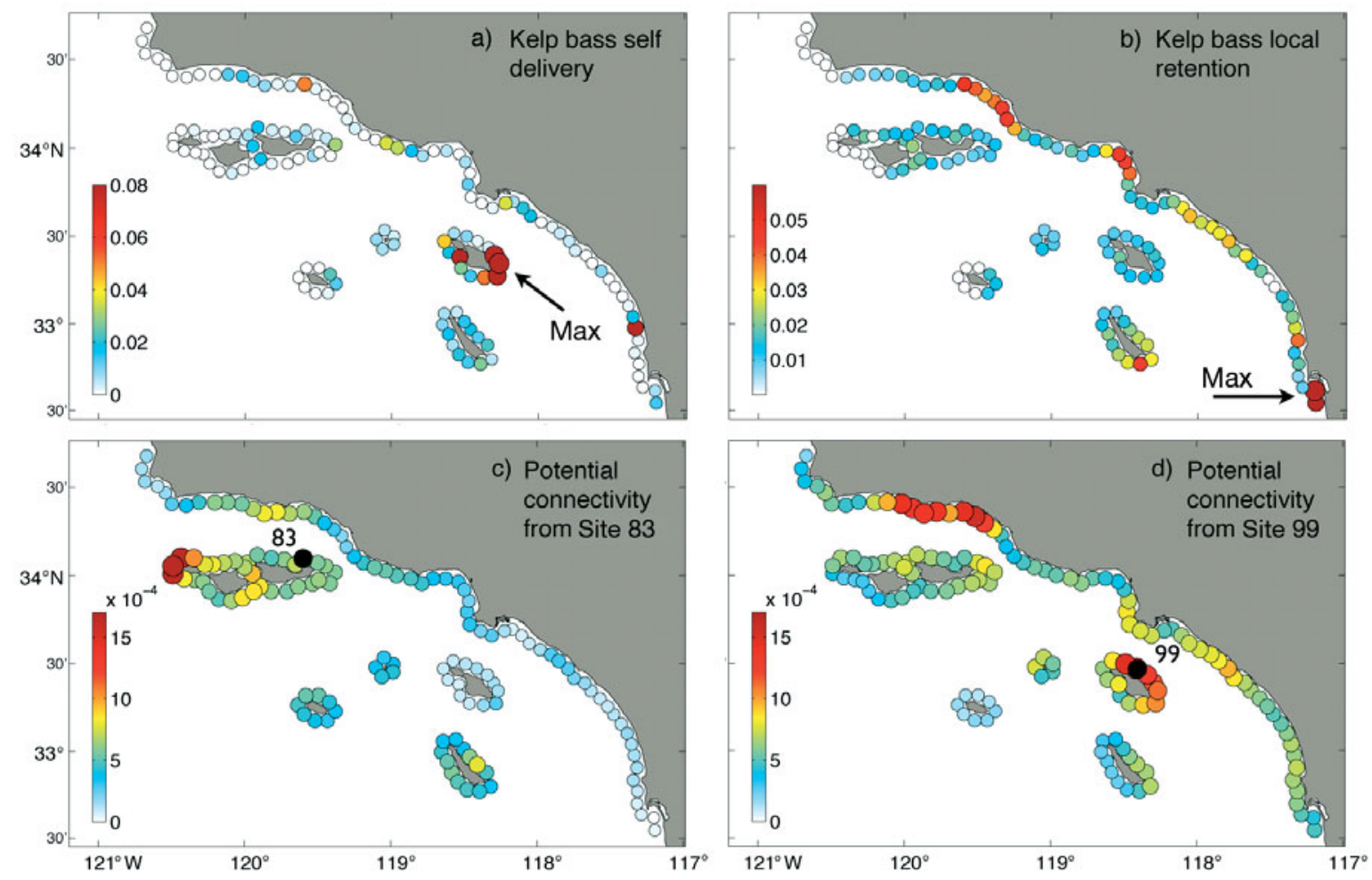

Fig. 11. (a) Self-delivery (the fraction of larvae arriving at a given site that were produced there) for fall spawning kelp bass. Location of maximum self-delivery is indicated by the arrow. (b) Local retention (the fraction of larvae produced at a given site that return) for fall spawning kelp bass. Location of maximum local retention is indicated by the arrow. For both (a) and (b), the coloraxis has been chosen to highlight differences between sites in self-delivery and local retention, respectively. (c) Potential connectivity from Site 83. (d) Potential connectivity from Site 99 
the mainland and at sites on the south of San Clemente Island (Fig. 11b). Interestingly, on the mainland there are hot spots of local retention in 2 major embayments: the Santa Monica Bay and the region around Ventura. The maximum value for local retention (19\%) was found at sites near Point Loma (Fig. 11b). Local retention is an important ecological metric and has been shown to play an important part in the self-persistence of a given location (Botsford et al. 2001, Byers \& Pringle 2006). Local retention measures how likely a population can self-persist without larval input from remote sources and is an important consideration for spatial management methods (Botsford et al. 2001, 2009). It is possible for a site to have high local retention but low self-delivery. In this case, a large fraction of larvae produced at a given site come back to it, but relative to the total amount of larvae settling there it is a small amount.

Like measures of self-connectivity, an important criterion for MPA design is the potential for larval dispersal to remote locations, or 'larval spillover'. In this case, it is more important to consider potential and not realized connectivity, as we expect MPAs to alter the magnitude and spatial patterns of larval production. Each row of the potential connectivity matrix describes the probability that a larva spawned at a given site $j$ will travel to another site $i$; this is commonly called the dispersal kernel (Largier 2003, Siegel et al. 2003). Using the potential connectivity matrix for summer spawning kelp bass (Fig. 3a), we show the dispersal kernels from Site 83 and Site 99 (Fig. 11c and d, respectively). It is evident that dispersal from these 2 locations is different. Existing MPAs are roughly situated in these sites, and the differences in their dispersal kernels provide insight into their utility. For example, Site 83 has the potential to send most of its larvae to the sites on the western side of San Miguel Island, whereas Site 99 has the potential to send larvae to nearby sites on Santa Catalina Island and mainland sites in the Santa Barbara Channel. These estimates of potential connectivity can be included in models of population dynamics. With this approach, spatially explicit information can be generated that is important to marine management (Botsford et al. 2009).

\section{Future work and model caveats}

The accuracy of our estimates of realized larval connectivity depends upon the ocean circulation model, the Lagrangian particle simulations, and our assumptions about larval production, mortality, and behavior. Dong et al. 2009 compared output from the circulation model with extensive observational data and found that the model reproduces a realistic mean state of the ocean circulation in the SCB and captures inter-annual and seasonal variability as well. For example, the circulation model has been applied to the study of island wakes in the SCB, has successfully simulated one of the strongest upwelling events in SCB, during March 2002, and, in terms of the seasonal mean, has been shown to reproduce the Santa Barbara Channel Eddy (Nishimoto \& Washburn 2002) with good agreement with observations.

Mitarai et al. (2009) showed that the Lagrangian particle simulations match well, qualitatively, with knowledge of the SCB ocean system. Simulated dispersal statistics (e.g. Lagrangian time and length scales and eddy diffusivities) were also found to agree with observations of these quantities (Swenson \& Niiler 1996). Clearly, the development of techniques that directly compare simulated estimates of larval dispersal with those made empirically is the next step and will be the focus of future work.

The limited domain is an important issue for consideration, as water parcels that are advected out of the domain are lost from the system although they might actually return. Hence, some sites, especially those near the domain boundaries, may have artificially reduced levels of potential connectivity. This boundary effect is seen to influence the location of sources of potential connectivity, which are found, generally, within the center of the domain with few sites, near the domain edge, generating strong source values (Fig. 4). This problem is discussed in greater detail by Mitarai et al. (2009).

Another caveat is that the model assumes zero larval mortality for all larvae. Larval mortality will be heterogeneous in the SCB owing to differences in temperature and food availability (e.g. Strathmann 1985). Larval mortality can be included in our modeling framework (Eq. 1) in the following way,

$$
L_{j i}=p_{j} W_{j i}\left(1-M_{j i}\right)
$$

where $M_{j i}$ is defined as the expected larval mortality for a larva spawned at a given location, $j$, as it disperses to a given destination, $i$. Including larval mortality will modify patterns of realized connectivity and estimates of larval settlement. However, quantifying larval mortality is beyond the scope of this study and is the subject of future work.

We modeled the dispersal of passive Lagrangian particles given some knowledge of the characteristics of kelp bass, kelp rockfish, and red abalone larvae (i.e. timing of spawning and pelagic larval duration). There is growing empirical evidence showing that vertical migratory swimming behavior exists in many pelagic larvae (Woodson \& McManus 2007, Edwards et al. 2008) and that this movement (and other movement strategies such as late stage active swimming to suit- 
able habitat) may have effects on the final patterns of potential larval connectivity (Metaxas 2001, Leis 2007). However, for kelp bass, kelp rockfish, and red abalone larvae, the assumption of passive transport may not be unreasonable. As described in the 'Methods' section, the kelp bass, kelp rockfish, and red abalone larvae are likely found in the near-surface currents. As such, passive Lagrangian particles will capture the ocean currents experienced by these larvae. Moreover, the thermocline in the SCB is deep (>50 $\mathrm{m}$ depth) relative to the lower depth range of many pelagic larvae exhibiting vertical migratory behaviors (e.g. Queiroga \& Blanton 2005). Hence, ocean current velocities affecting larval transport will change little with depth (Harms \& Winant 1998). Consequently, incorporating vertical larval mobility into Lagrangian particle simulations of larval connectivity in the SCB may affect results only minimally. This was also shown by Siegel et al. (2008) in idealized Lagrangian particle simulations of larval dispersal along the Central California Coast. While recognizing the potential for larvae to alter their dispersal patterns with behavior, we suggest that the passive case presented here provides the 'base case' by which future comparisons incorporating larval behavior can be made.

Acknowledgements. The authors thank S. Gaines, R. Warner, C. Costello, B. Kendall, B. Kinlan, C. White, T. Chaffey, S. Bonhommeau, and C. Swan for their indefatigable advice and insight. This work was supported by the National Science Foundation, the California Coastal Conservancy, the University of California Coastal Environmental Quality Initiative, the National Oceanic and Atmospheric Administration, the National Aeronautics and Space Administration, the US Geological Survey, and the US Environmental Protection Agency. The authors also thank the Partnership for Interdisciplinary Studies of Coastal Oceans and the Cooperative Research and Assessment of Nearshore Ecosystems Program (specifically, the principal investigators: T. Anderson, M. Edwards, J. Carroll, D. Schroeder, M. Carr, C. Syms, and D. Pondella) for the use of the CRANE data. This is PISCO publication number 331.

\section{LITERATURE CITED}

Amundsen PA, Lafferty KD, Knudsen R, Primicerio R, Klemetsen A, Kuris AM (2009) Food web topology and parasites in the pelagic zone of a subarctic lake. J Anim Ecol 78:563-572

Armsworth PR (2002) Recruitment limitation, population regulation, and larval connectivity in reef fish metapopulations. Ecology 83:1092-1104

Baums IB, Paris CB, Cherubin LM (2006) A bio-oceanographic filter to larval dispersal in a reef-building coral. Limnol Oceanogr 51:1969-1981

Bode M, Burrage K, Possingham HP (2008) Using complex network metrics predicts the persistence of metapopulations with asymmetric connectivity patterns. Ecol Model 214:201-209
Bonhommeau S, Blanke B, Treguier AM, Grima N and others (2009) Can the European eel larvae cross the Atlantic Ocean in 6 months? Fish Oceanogr 18:371-385

Botsford LW, Hastings A, Gaines SD (2001) Dependence of sustainability on the configuration of marine reserves and larval dispersal distance. Ecol Lett 4:144-150

Botsford LW, Micheli F, Hastings A (2003) Principles for the design of marine reserves. Ecol Appl 13:25-31

Botsford LW, White JW, Coffroth MA, Paris CB and others (2009) Connectivity and resilience of coral reef metapopulations in marine protected areas: matching empirical efforts to predictive needs. Coral Reefs 28:327-337

Byers J, Pringle J (2006) Going against the flow: retention, range limits and invasions in advective environments. Mar Ecol Prog Ser 313:27-41

> Carr MH (1994) Effects of macroalgal dynamics on recruitment of a temperate reef fish. Ecology 75:1320-1333

Carton JA, Chepurin G, Cao X (2000a) A simple ocean data assimilation analysis of the global upper ocean 1950-95. Part II: Results. J Phys Oceanogr 30:311-326

Carton JA, Chepurin G, Cao X, Giese B (2000b) A simple ocean data assimilation analysis of the global upper ocean 1950-95. Part I: methodology. J Phys Oceanogr 30: 294-309

Clark R, Christensen J, Caldow C, Allen J, Murry M, MacWilliams S (2005) A biogeographic assessment of the Channel Islands National Marine Sanctuary: a review of boundary expansion concepts for NOAA's National Marine Sanctuary Program. Silver Spring, MD. NOAA Technical Memorandum NOS NCCOS 21, p 1-240

- Cowen RK (1985) Large scale pattern of recruitment by the labrid, Semicossyphus pulcher: causes and implications. J Mar Res 43:719-742

Cowen RK, Sponaugle S (2008) Larval dispersal and marine population connectivity. Annu Rev Mar Sci 1:443-466

Cowen RK, Lwiza K, Sponaugle S, Paris C, Olson DB (2000) Connectivity of marine populations: open or closed? Science 287:857-859

Cowen RK, Paris C, Srinivasan A (2006) Scaling of connectivity in marine populations. Science 311:522-527

Cudney-Bueno R, Lavin MF, Marinone SG, Raimondi PT, Shaw WW (2009) Rapid effects of marine reserves via larval dispersal. PLoS ONE 4(1):e4140, doi:10.1371/journal. pone. 0004140

DeMartini EE (1987) Tests of ovary subsampling options and preliminary estimates of batch fecundity for two Paralabrax species. CCOFI Rep 28:168-170

> Dever E, Winant C (2002) The evolution and depth structure of shelf and slope temperatures and velocities during the 1997-1998 El Niño near Point Conception, California. Prog Oceanogr 54:77-103

Di Lorenzo E (2003) Seasonal dynamics of the surface circulation in the Southern California Current System. Deep-Sea Res II 50:2371-2388

> Dong C, McWilliams JC (2007) A numerical study of island wakes in the Southern California Bight. Cont Shelf Res 27:1233-1248

> Dong C, McWilliams JC, Shchepetkin A (2007) Island wakes in deep water. J Phys Oceanogr 37:962-981

Dong C, Idica E, McWilliams JC (2009) Circulation and multiple-scale variability in the Southern California Bight. Prog Oceanogr 82:168-190

Dunne JA (2006) The network structure of food webs. In: Pascual M, Dunne JA (eds) Ecological networks: linking structure to dynamics in food webs. Oxford University Press, New York, p 1-416

> Edwards KP, Hare JA, Werner FE (2008) Dispersal of black sea bass (Centropristis striata) larvae on the southeast US 
continental shelf: results of a coupled vertical larval behavior-3D circulation model. Fish Oceanogr 17: 299-315

Erisman B, Allen L (2006) Reproductive behaviour of a temperate serranid fish, Paralabrax clathratus (Girard), from Santa Catalina Island, California, USA. J Fish Biol 68: 157-184

Findlay A, Allen L (2002) Temporal patterns of settlement in the temperate reef fish Paralabrax clathratus. Mar Ecol Prog Ser 238:237-248

Gaines SD, Gaylord B, Largier J (2003) Avoiding current oversights in marine reserve design. Ecol Appl 13:32-46

> Gallego A, North E, Petitgas P (2007) Introduction: status and future of modelling physical-biological interactions during the early life of fishes. Mar Ecol Prog Ser 347:121-126

Gawarkiewicz G, Monismith S, Largier J (2007) Observing larval transport processes affecting population connectivity: progress and challenges. Oceanography 20:40-53

Gaylord B, Gaines SD, Siegel DA, Carr MH (2005) Marine reserves exploit population structure and life history in potentially improving fisheries yields. Ecol Appl 15: $2180-2191$

Gerber L, Botsford L, Hastings A, Possingham H, Gaines SD, Palumbi S, Andelman S (2003) Population models for marine reserve design: a retrospective and prospective synthesis. Ecol Appl 13:47-64

Gilbert-Horvath EA, Larson RJ, Garza JC (2006) Temporal recruitment patterns and gene flow in kelp rockfish (Sebastes atrovirens). Mol Ecol 15:3801-3815

Haaker PL, Karpov K, Rogers-Bennett L, Taniguchi I, Friedman CS, Tegner MJ (2001) Abalone. In: California's living marine resources: a status report. California Department of Fish and Game, Sacramento, CA, p 89-97

Halpern BS, Warner RR (2003) Matching marine reserve design to reserve objectives. Proc Biol Sci 270:1871-1878

Harms S, Winant CD (1998) Characteristic patterns of the circulation in the Santa Barbara Channel. J Geophys Res 103:3041-3065

Hastings A, Botsford L (2006) Persistence of spatial populations depends on returning home. Proc Natl Acad Sci USA 103:6067-6072

> Hickey BM (1992) Circulation over the Santa Monica-San Pedro basin and shelf. Prog Oceanogr 30:37-115

Johnson M (1959) The offshore drift of larvae of the California spiny lobster Panulirus interruptus. CCOFI Rep 7:147-161

Kim H, Kimura S, Shinoda A, Kitagawa T, Sasai Y, Sasaki H (2007) Effect of El Niño on migration and larval transport of the Japanese eel (Anguilla japonica). ICES J Mar Sci 64:1387-1395

Kimura S, Dos K, Coward A (1999) Numerical simulation to resolve the issue of down-stream migration of the Japanese eel. Mar Ecol Prog Ser 186:303-306

Kinlan B, Gaines SD (2003) Propagule dispersal in marine and terrestrial environments: a community perspective. Ecology 84:2007-2020

Kinlan B, Gaines SD, Lester S (2005) Propagule dispersal and the scales of marine community process. Divers Distrib 11:139-148

Largier J (2003) Considerations in estimating larval dispersal distances from oceanographic data. Ecol Appl 13:S71-S89

Leighton DL (1974) The influence of temperature on larval and juvenile growth in three species of southern California abalones. Fish Bull 72:1137-1145

Leis J (2007) Behaviour as input for modelling dispersal of fish larvae: behaviour, biogeography, hydrodynamics, ontogeny, physiology and phylogeny meet hydrography. Mar Ecol Prog Ser 347:185-193

Love MS (1991) Probably more than you want to know about the fishes of the Pacific Coast. Really Big Press, Santa Barbara, CA

Lowe CG, Bray R (2006) Movements and activity patterns. In: Allen LG, Pondella DJ II, Horn MH (eds) The ecology of marine fishes: California and adjacent waters. University of California Press, Berkeley, CA, p 524-533

Lowe CG, Topping DT, Cartamil DP, Papastamatiou YP (2003) Movement patterns, home range, and habitat utilization of adult kelp bass Paralabrax clathratus in a temperate no-take marine reserve. Mar Ecol Prog Ser 256:205-216

Lynn R, Bograd S (2002) Dynamic evolution of the 1997-1999 El Niño-La Niña cycle in the southern California Current system. Prog Oceanogr 54:59-75

May RM, Lloyd AL (2001) Infection dynamics on scale-free networks. Phys Rev E 64:1-4

Metaxas A (2001) Behaviour in flow: perspectives on the distribution and dispersion of meroplanktonic larvae in the water column. Can J Fish Aquat Sci 58:86-98

Miller DJ, Lea RN (1976) Guide to the coastal marine fishes of California. Fish Bulletin 157. State of California Department of Fish and Game, Sacramento, CA

Mitarai S, Siegel DA, Watson JR, Dong C, McWilliams JC (2009) Quantifying connectivity in the coastal ocean with application to the Southern California Bight. J Geophys Res, C10026, doi:10.1029/2008JC005166

Moser H, Charter R, Watson W, Ambrose D (2001) The CALCOFI ichthyoplankton time series: potential contributions to the management of rocky-shore fishes. CCOFI Rep 42:112-128

Nelson PA (2001) Behavioral ecology of young-of-the-year kelp rockfish, Sebastes atrovirens Jordan and Gilbert (Pisces: Scorpaenidae). J Exp Mar Biol Ecol 256:33-50

Neubert M, Caswell H (2000) Demography and dispersal: calculation and sensitivity analysis of invasion speed for structured populations. Ecology 81:1613-1628

- Nishimoto M, Washburn L (2002) Patterns of coastal eddy circulation and abundance of pelagic juvenile fish in the Santa Barbara Channel, California, USA. Mar Ecol Prog Ser 241:183-199

Palumbi S (2003) Population genetics, demographic connectivity, and the design of marine reserves. Ecol Appl 13:146-158

Paris C, Cowen RK (2004) Direct evidence of a biophysical retention mechanism for coral reef fish larvae. Limnol Oceanogr 49:1964-1979

Paris C, Cowen RK, Claro R, Lindeman K (2005) Larval transport pathways from Cuban snapper (Lutjanidae) spawning aggregations based on biophysical modeling. Mar Ecol Prog Ser 296:93-106

Pfeiffer-Herbert AS, McManus MA, Raimondi PT, Chao Y, Chai F (2007) Dispersal of barnacle larvae along the central California coast: a modeling study. Limnol Oceanogr 52:1559-1569

Pineda J (1994) Spatial and temporal patterns in barnacle settlement rate along a southern California rocky shore. Mar Ecol Prog Ser 107:125-138

Planes S, Jones GP, Thorrold SR (2009) Larval dispersal connects fish populations in a network of marine protected areas. Proc Natl Acad Sci USA 106:5693-5697

> Pringle J (1986) California spiny lobster (Panulirus interruptus) larval retention and recruitment: a review and synthesis. Can J Fish Aquat Sci 43:2142-2152

> Pringle J, Wares J (2007) Going against the flow: maintenance of alongshore variation in allele frequency in a coastal ocean. Mar Ecol Prog Ser 335:69-84

Queiroga H, Blanton JO (2005) Interactions between behaviour 
and physical forcing in the control of horizontal transport of decapod crustacean larvae. Adv Mar Biol 47:107-214

Rasmussen L, Cornuelle B, Levin L, Largier J (2009) Effects of small-scale features and local wind forcing on tracer dispersion and estimates of population connectivity in a regional scale circulation model. J Geophys Res 114, C01012, doi: 10.1029/2008JC004777

Roberts CM, Andelman S, Branch G, Bustamante RH and others (2003) Ecological criteria for evaluating candidate sites for marine reserves. Ecol Appl 13:S199-S213

Rogers-Bennett L, Haaker P, Karpov K, Kushner D (2002) Using spatially explicit data to evaluate marine protected areas for abalone in Southern California. Conserv Biol 16:1308-1317

Romero M (1988) Life history of the kelp rockfish, Sebastes atrovirens (Scorpaenidae). MA Thesis. San Francisco State University

Roughgarden J, Iwasa Y, Baxter C (1985) Demographic theory for an open marine population with space-limited recruitment. Ecology 66:54-67

Roughgarden J, Gaines SD, Possingham H (1988) Recruitment dynamics in complex life cycles. Science 241: 1460-1466

Selkoe KA, Vogel A, Gaines SD (2007) Effects of ephemeral circulation on recruitment and connectivity of nearshore fish populations spanning Southern and Baja California. Mar Ecol Prog Ser 351:209-220

Selkoe KA, Henzler CM, Gaines SD (2008) Seascape genetics and the spatial ecology of marine populations. Fish Fish 9:363-377

Shchepetkin AF, McWilliams JC (2005) The regional oceanic modeling system (ROMS): a split-explicit, free-surface, topography-following-coordinate oceanic model. Ocean Model 9:347-404

Shima J, Findlay A (2002) Pelagic larval growth rate impacts benthic settlement and survival of a temperate reef fish. Mar Ecol Prog Ser 235:303-309

Editorial responsibility: Steven Morgan,

Bodega Bay, California, USA
Siegel DA, Kinlan B, Gaylord B, Gaines SD (2003) Lagrangian descriptions of marine larval dispersion. Mar Ecol Prog Ser 260:83-96

Siegel DA, Mitarai S, Costello CJ, Gaines SD, Kendall BE, Warner RR, Winters KB (2008) The stochastic nature of larval connectivity among nearshore marine populations. Proc Natl Acad Sci USA 105:8974-8979

Strathmann R (1985) Feeding and nonfeeding larval development and life-history evolution in marine invertebrates. Annu Rev Ecol Syst 16:339-361

Sverdrup HU (1941) The Pacific Ocean. Science 94:287-293

Swenson M, Niiler P (1996) Statistical analysis of the surface circulation of the California Current. J Geophys Res 101: 22631-22646

Treml EA, Halpin PN, Urban DL, Pratson LF (2008) Modeling population connectivity by ocean currents, a graph-theoretic approach for marine conservation. Landscape Ecol 23:19-36

Urban D, Keitt T (2001) Landscape connectivity: a graphtheoretic perspective. Ecology 82:1205-1218

Vance R (1973) On reproductive strategies in marine benthic invertebrates. Am Nat 107:339-352

Warner R, Cowen R (2002) Open vs. closed marine populations: synthesis and analysis of the evidence. Bull Mar Sci 70:245-337

White C (2009) Density dependence and the economic efficacy of marine reserves. Theor Ecol 2:127-138

Woodson CB, McManus MA (2007) Foraging behavior can influence dispersal of marine organisms. Limnol Oceanogr 52:2701-2709

Young PH (1963) The kelp bass (Paralabrax clathratus) and its fishery, 1947-1958. Fish Bulletin 122. California Department of Fish and Game, Sacramento, CA, p 1-67

Zacherl DC (2005) Spatial and temporal variation in statolith and protoconch trace elements as natural tags to track larval dispersal. Mar Ecol Prog Ser 290:145-163

Submitted: June 2, 2009; Accepted: October 18, 2009

Proofs received from author(s): February 11, 2010 